\title{
Development of Feeder Messenger Wire Type Overhead Contact Line with One Copper Messenger Wire
}

\author{
Takahiro HAMADA \\ Researcher, \\ Atsushi IWAINAKA \\ Contact Line Structures, Power Supply Technology Div.
}

\begin{abstract}
Feeder messenger wire type overhead contact lines have drawn attention recently from the viewpoint of labor-saving for maintenance. A type that uses two PH356m $\mathrm{m}^{2}$ messenger wires was introduced into the Tokyo district, while another that uses an SBTACSR730 $\mathrm{mm}^{2}$ messenger wire into the Kansai district. In terms of the number of messenger wires, the one-wire type is more useful, as it involves a smaller number of parts. As the material for the wire, copper is better than aluminum, since it does not require connection with different metals. To realize the advantages of the two systems, therefore, we developed a feeder messenger wire type overhead contact line that has only one copper messenger wire.
\end{abstract}

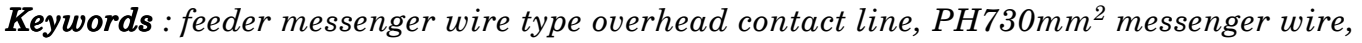
current collecting characteristics

\section{Introduction}

Feeder messenger wire type overhead contact lines have a structure to combine the function of feeder with the messenger wire. They have drawn attention recently in Japan from the viewpoint of labor-saving for maintenance. They use two hard-drawn copper stranded conductor PH356 $\mathrm{mm}^{2}$ messenger wires in the Tokyo district, and an aluminum conductor steel-reinforced SBTACSR730 $\mathrm{mm}^{2}$ messenger wire in the Kansai district. In terms of the number of messenger wires, the one-wire type is more useful as it involves a smaller number of parts, and copper is better as the material for the wire than aluminum since it does not require connection with different metals. Therefore, we promoted this research for the purpose of developing a feeder messenger wire type overhead contact line that has only one copper messenger wire to realize the advantages of the two systems.

In order to determine what wires suit the new overhead contact line, we chose a narrow-gauge line in Tokyo as a test site, studied whether electrical and mechanical characteristics of wires satisfy the standard values, and examined the current collecting characteristics of various types of wires through simulation. As a result, it was proved that the $\mathrm{PH} 730 \mathrm{~mm}^{2}$ messenger wire was the most appropriate in the overcrowded railway sections in Tokyo.

Based on this result, we actually constructed a $\mathrm{PH} 730 \mathrm{~mm}^{2}$ messenger wire and investigated its current collecting characteristics by using current collection testing equipment to find that standard values were all satisfied at the speed of $160 \mathrm{~km} / \mathrm{h}$. It was also proved that this wire type could be used for operation at speeds up to $160 \mathrm{~km} / \mathrm{h}$.

\section{Examination of the optimum wires}

Table 1 lists the wires examined as candidates of one-
Table 1 Dimensions of wire

\begin{tabular}{|c|c|c|c|}
\hline Wire name & Types of wire & $\begin{array}{l}\text { Total number } \\
\text { of strands }\end{array}$ & $\begin{array}{l}\text { Diameter of } \\
\text { strand }[\mathrm{mm}]\end{array}$ \\
\hline \multirow{4}{*}{$\begin{array}{l}\text { Hard-drawn copper } \\
\text { stranded conductor }\end{array}$} & PH670mm ${ }^{2}$ & 127 & 2.6 \\
\hline & $\mathrm{PH} 730 \mathrm{~mm}^{2}$ & 91 & 3.2 \\
\hline & PH770mm² & 61 & 4.0 \\
\hline & $\mathrm{PH} 40 \mathrm{~mm}^{2}$ & 127 & 2.9 \\
\hline \multirow{4}{*}{$\begin{array}{l}\text { Thermal-proof hard- } \\
\text { drawn copper stranded } \\
\text { conductor }\end{array}$} & THDC670 $\mathrm{mm}^{2}$ & 127 & 2.6 \\
\hline & THDC730mm ${ }^{2}$ & 91 & 3.2 \\
\hline & THDC $770 \mathrm{~mm}^{2}$ & 61 & 4.0 \\
\hline & THDC $840 \mathrm{~mm}^{2}$ & 127 & 2.9 \\
\hline
\end{tabular}

messenger wire. We examined the current capacity, wire resistance, tensile strength, minimum hanger length and current collecting characteristics, to determine the applicability of these wires to the one-messenger wire system.

\subsection{Current capacity}

We examined whether the wire temperature is below the allowable limit at the conditions in Table 2 . The allowable temperature is $90{ }^{\circ} \mathrm{C}$ for the hard drawn copper stranded conductor $(\mathrm{PH})$ and $150{ }^{\circ} \mathrm{C}$ for the thermalproof hard drawn copper stranded conductor (THDC). Figure 1 shows the wire temperature rises when a current of $855 \mathrm{~A}$, which is the maximum value for wires used in Tokyo, flows for 3,600 seconds. The shaded portion represents the surrounding temperature of $35^{\circ} \mathrm{C}$,

Table 2 Conditions of temperature calculation

\begin{tabular}{|l|l|}
\hline Surrounding temperature & $35^{\circ} \mathrm{C}$ (rush hours in the morning) \\
\hline Insolation & $0.1 \mathrm{~W} / \mathrm{cm}^{2}$ \\
\hline Emissivity & 0.9 \\
\hline Wind velocity & $0.5 \mathrm{~m} / \mathrm{s}$ \\
\hline Load current & $\begin{array}{l}855 \mathrm{~A} \text { (Maximum current at a line in } \\
\text { Tokyo) for 3,600 seconds }\end{array}$ \\
\hline
\end{tabular}




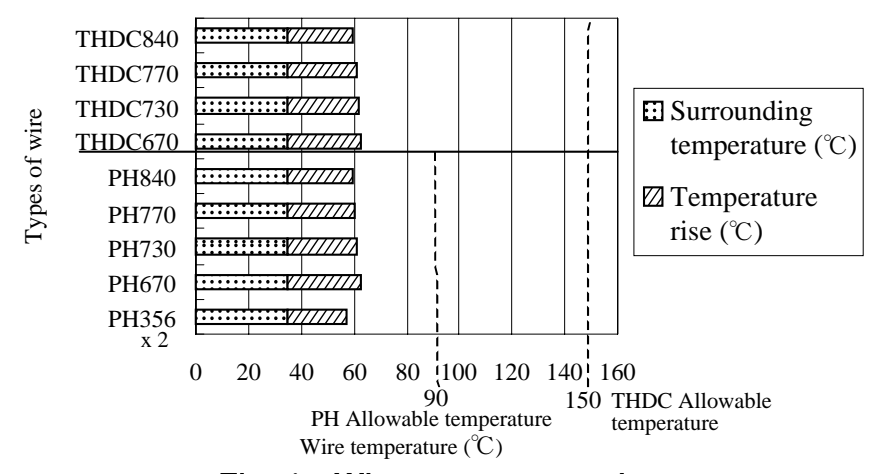

Fig. 1 Wire temperature rises

and the portion of slash mark the temperature rises by the Joule heat. There are no wires of THDC or PH that show a temperature rise over the allowable limit under this condition.

\subsection{Wire resistance}

To evaluate the wire resistance, we compared several kinds of messengers with two PH356 $\mathrm{mm}^{2}$ messenger wires currently used on the narrow-gauge lines in Tokyo. In Fig. 2, the slash lined bars show the resistance after the temperature rise at an 855 A current flow and the shaded bars show the wire resistance at $20{ }^{\circ} \mathrm{C}$. A comparison of the resistance of two $\mathrm{PH} 356 \mathrm{~mm}^{2}$ wires with that of test wires at $20{ }^{\circ} \mathrm{C}$ (shaded bar), proves that the resistance of THDC $670 \mathrm{~mm}^{2}$ wire and $\mathrm{PH} 670 \mathrm{~mm}^{2}$ wire is higher than that of two PH356 $\mathrm{mm}^{2}$ wires. Moreover, in the case of the resistance after temperature rise (slash), only the resistance of THDC670 $\mathrm{mm}^{2}$ wire and $\mathrm{PH} 670 \mathrm{~mm}^{2}$ wire is higher than that of two $\mathrm{PH} 356 \mathrm{~mm}^{2}$ wires.

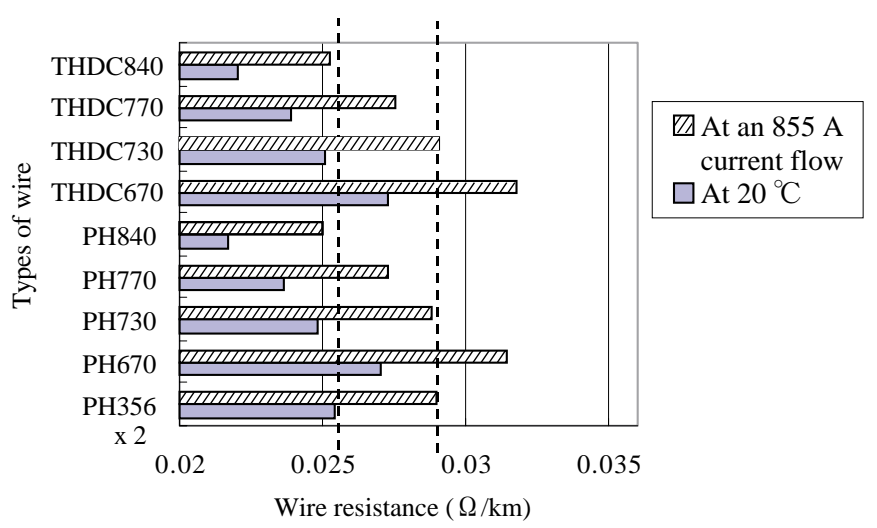

Fig. 2 Wire resistance

\subsection{Tensile strength}

Since it is assumed that this catenary system is constructed to a standard tension of $39.2 \mathrm{kN}$, it is a condition that the tensile strength is set at over $86.24 \mathrm{kN}$, as the safety factor of copper is 2.2 in Japan. All the tensile strengths for the test wires referred to in this paper are over $86.24 \mathrm{kN}$.

\subsection{Minimum hanger length}

We calculated the minimum hanger length on the assumption that the messenger wire tension is $39.2 \mathrm{kN}$; contact wire tension is $14.7 \mathrm{kN}$; and span length is 50 $\mathrm{m}$. When we assume a standard system height $(850 \mathrm{~mm})$ equivalent to that of existing feeder messenger wire type overhead contact line in Tokyo, only the minimum hanger length of $\mathrm{PH} 840 \mathrm{~mm}^{2}$ wire is less than $150 \mathrm{~mm}$. If the system height is assumed to be $960 \mathrm{~mm}$, the minimum hanger length of $\mathrm{PH} 840 \mathrm{~mm}^{2}$ wire is larger than $150 \mathrm{~mm}$.

\subsection{Current collecting characteristics}

We calculated the contact loss rate and contact wire uplift and strain at support by simulation when we use each tested wire as a messenger, and compared the results with the standard values that can realize stable current collection. Tables 3 and 4 show simulation conditions and standard values, respectively. Figure 3 shows the contact loss rate of the 2 nd pantograph. As a result of the simulation, the contact loss rate of the 1st pantograph was set at $0 \%$ for all wires and contact loss rates of the 2nd and 3rd pantographs became several percent at speeds higher than $180 \mathrm{~km} / \mathrm{h}$. However, the contact loss rate up to $160 \mathrm{~km} / \mathrm{h}$, which is practically the highest speed on narrow-gauge lines, is $0 \%$. Figures 4 and 5 show the contact wire uplift and strain at support, re-

Table 3 Conditions of simulation

\begin{tabular}{|l|l|l|}
\hline \multirow{3}{*}{$\begin{array}{l}\text { Composition of } \\
\text { Catenary }\end{array}$} & Contact wire & GTM-SN170 $\mathrm{mm}^{2}$ \\
\cline { 2 - 3 } & Messenger tension & $39.2 \mathrm{kN}$ \\
\cline { 2 - 3 } & Contact wire tension & $14.7 \mathrm{kN}$ \\
\cline { 2 - 3 } & Span length & $50 \mathrm{~m}$ \\
\cline { 2 - 3 } & Distance between two hangers & $5 \mathrm{~m}$ \\
\cline { 2 - 3 } & System height & $850 \mathrm{~mm}$ \\
\hline \multirow{3}{*}{ Pantograph } & Type & PS26 \\
\cline { 2 - 3 } & Number & 3 \\
\cline { 2 - 3 } & Distance & $80 \mathrm{~m}, 60 \mathrm{~m}$ \\
\hline Speed & $100 \sim 200 \mathrm{~km} / \mathrm{h}$ \\
\hline
\end{tabular}

Table 4 Standard values of current collecting characteristics

\begin{tabular}{|l|l|}
\hline Contact loss rate & Less than $5 \%$ \\
\hline Contact wire strain at support & Less than $500 \times 10^{-6}$ \\
\hline Contact wire uplift at support & Less than $70 \mathrm{~mm}$ \\
\hline
\end{tabular}

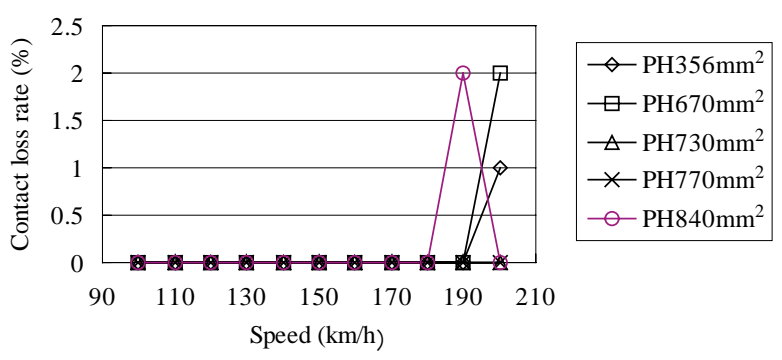

Fig. 3 Simulation results (Contact loss rate) 


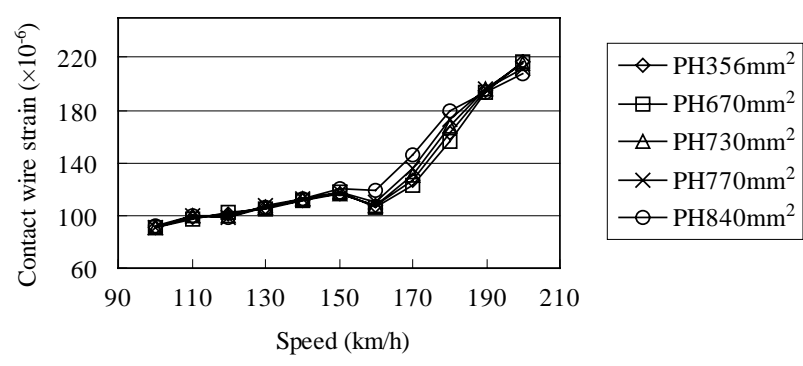

Fig. 4 Simulation results (Contact wire strain at support)

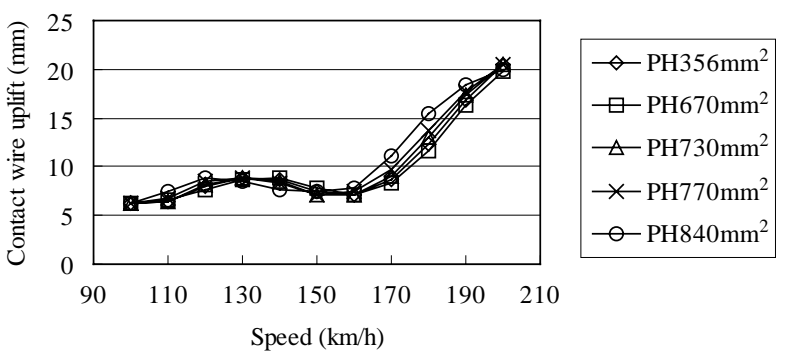

Fig. 5 Simulation results (Contact wire uplift at support)

spectively. Either is not over the standard value up to the speed of $200 \mathrm{~km} / \mathrm{h}$ with any wire.

\subsection{Examination results}

Since the current capacity, tensile strength and current collecting characteristics satisfied the standard values no matter which wire we use, we judged the appropriateness of the wires based on the wire resistance. Table 5 shows the judgment results. Under the condition of an 855 A current flow, we marked "O" if the wire resistance satisfies the judgment standard and " $\mathrm{X}$ " if not. Consequently, we reached a conclusion that use of $\mathrm{PH} 730 \mathrm{~mm}^{2}$ wire is appropriate with respect to the 855 A current capacity.

Table 5 Judgment results

\begin{tabular}{|l|c|}
\hline & Judgment \\
\hline PH670mm & X \\
\hline PH730mm & O \\
\hline PH770mm & O \\
\hline PH840mm & O \\
\hline THDC670mm & \\
\hline THDC730mm & O \\
\hline THDC770mm & X \\
\hline THDC $840 \mathrm{~mm}^{2}$ & O \\
\hline
\end{tabular}

\section{Test by current collection testing equipment}

The current collection testing equipment of the Railway Technical Research Institute used for this test has a full length of $500 \mathrm{~m}$ and can carry out running tests up to the speed of $160 \mathrm{~km} / \mathrm{h}$, by using an actual contact wire and pantograph. We chose a $\mathrm{PH} 730 \mathrm{~mm}^{2}$ wire among the wires which were appropriate for the test in Chapter 2, constructed it as a messenger for the testing equipment, and examined its current collecting characteristics. Test conditions are as follows.

\subsection{Test conditions}

3.1.1 Basic composition of catenary and used pantograph

The catenary of the testing equipment was composed to the specification shown in Table 6 , which is used for narrow-gauge lines in Tokyo. This system has two PH356mm ${ }^{2}$ messenger wires and a GTM-SN170 $\mathrm{mm}^{2}$ contact wire.

Table 6 Test conditions

\begin{tabular}{|l|l|l|}
\hline \multirow{4}{*}{$\begin{array}{l}\text { Composition of } \\
\text { catenary }\end{array}$} & Messenger wire & PH730mm \\
\cline { 2 - 3 } & Contact wire & GTM-SN170mm \\
\cline { 2 - 3 } & Messenger wire tension & $39.2 \mathrm{kN}$ \\
\cline { 2 - 3 } & Contact wire tension & $14.7 \mathrm{kN}$ \\
\cline { 2 - 3 } & Span length & $50 \mathrm{~m}$ \\
\cline { 2 - 3 } & Distance between two hangers & $5 \mathrm{~m}$ \\
\cline { 2 - 3 } & System height & $1000 \mathrm{~mm}$ \\
\hline Pantograph & Type & PS26 \\
\cline { 2 - 3 } & Static upward force & $53.9 \mathrm{kN}$ \\
\hline Speed & $80,100,120,140,150,160 \mathrm{~km} / \mathrm{h}$ \\
\hline
\end{tabular}

\subsubsection{Pantograph damper}

We used a PS26 pantograph with a damper currently used for the limited express trains on narrow-gauge lines, and also examined the case where the damper is removed to assume common vehicles.

Figure 6 shows the catenary composition and the measuring points of testing equipment.

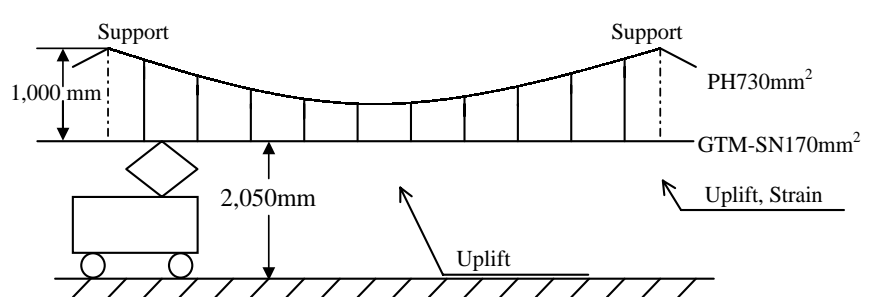

Fig. 6 Catenary composition and measuring points of current collection testing equipment

\subsection{Test results}

The test results are shown in Figs. 7 to 9 when messenger tension is set at the standard value $(39.2 \mathrm{kN})$. In these Figures, the results in the cases with and without pantograph dampers are compared.

\subsubsection{Contact loss rate}

Figure 7 shows the relation between speed and contact loss rate. In the case where there is a pantograph damper, it is $0.26 \%$ at the speed of about $156 \mathrm{~km} / \mathrm{h}$. However, it is substantially less than the standard value of $5 \%$. In the case where there are no dampers, the contact loss is not generated up to about $150 \mathrm{~km} / \mathrm{h}$.

\subsubsection{Contact wire strain}

Figure 8 shows the relation between speed and con- 


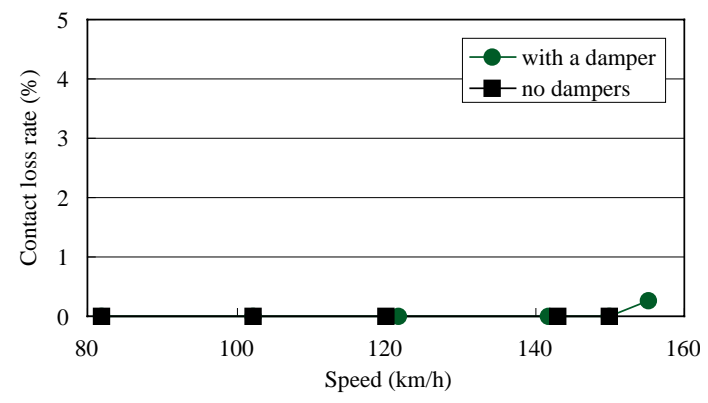

Fig. 7 Test results (Contact loss rate)

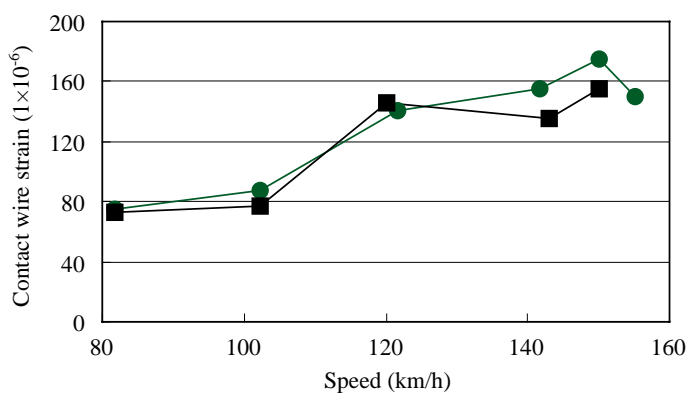

Fig. 8 Test results (Contact wire strain at support)

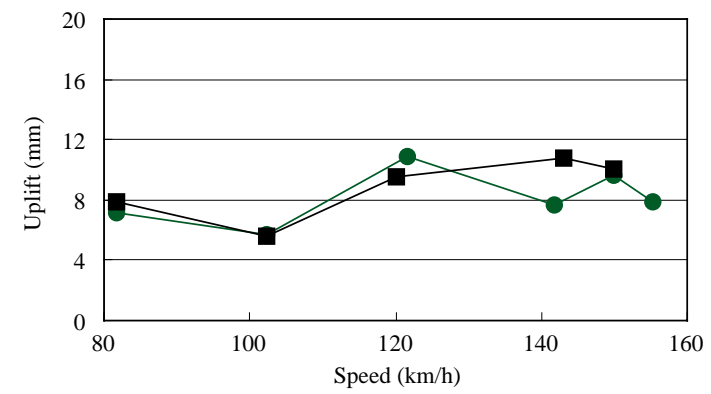

Fig. 9 Test results (Contact wire uplift at support)

tact wire strain at support. The allowable stress for oscillating fatigue of copper contact wire is set at $60 \mathrm{MPa}$ based on the results of an experiment, or $500 \times 10^{-6}$ when converted into strain. Since the strain in this experiment is considered as the difference between the maximum and minimum values, the standard value of contact wire strain is set at $1000 \times 10^{-6}$ at the full amplitude. As it takes a maximum value at about $150 \mathrm{~km} / \mathrm{h}$, the value is $175 \times 10^{-6}$ at the maximum, which is considerably less than the standard value of contact wire strain.

\subsubsection{Contact wire uplift}

Figure 9 shows the relation between speed and contact wire uplift at support. As it takes a maximum value of $10.8 \mathrm{~mm}$ at about $120 \mathrm{~km} / \mathrm{h}$, it is considerably to be less than the standard value of contact wire uplift at support.

Figures 7 to 9 show the difference in the characteristics when a pantograph damper is used or not, we understand that the contact wire strain in the case where no dampers are used is a little smaller. Regarding other items, the current collecting characteristics are virtually not different from each other irrespective of whether a damper is used or not.

\subsection{Conclusion of the test}

When a PH730 $\mathrm{mm}^{2}$ wire is selected and constructed to the standard tension of $39.2 \mathrm{kN}$ as a messenger, the contact loss rate, contact wire strain and contact wire uplift at support satisfy the standard values. We understood that this system can be used up to $160 \mathrm{~km} / \mathrm{h}$. Moreover, when the pantograph damper is removed, it turns out that the current collecting characteristics do not change much or there are no problems in running. However, in the actual case where two or more pantographs are used, and the state of catenary is considered to be worse than on this testing equipment, the field running tests need to be performed for final judgment.

\section{Conclusion}

We performed this research to investigate high-quality feeder messenger wire type overhead contact lines and examined a wire of copper system. We selected a $\mathrm{PH} 730 \mathrm{~mm}^{2}$ wire and used it as a messenger wire, and examined the current collecting characteristics at the speed up to $160 \mathrm{~km} / \mathrm{h}$ by using current collection testing equipment. Although this system has a heavy large-diameter wire and may require difficult construction work, no important problems were experienced in the construction of the test equipment. It is required, however, to investigate the problems that will arise in the construction work on actual railway lines in service.

\section{References}

1) Shimodaira, Y., Sato, Y. and Kawanaka, Y.: "Experiment results of feeder messenger wire type overhead contact line," I.E.E. JAPAN (in Japanese), TER-9854, 1999.

2) Shimodaira, Y.: "Study on messenger wire of wire type overhead contact line," National convention of I.E.E. JAPAN (in Japanese), 5-212, 1999.

3) Iwainaka, A., Suzuki, A.: "Current collecting characteristics of one line copper feeder messenger wire type over head contact line," J-RAIL'99 (in Japanese), pp.265, 1999. 